\title{
Ingraining goal orientation behavior among Malaysian adolescents using Solution-Focused Group Work (SFGW)
}

\author{
Ratnadevi R.Shunmugam ${ }^{1 *}$, Sidek Mohd. Noah ${ }^{2}$, Wan Marzuki Wan Jaafar ${ }^{3}$ \\ ${ }^{123}$ University of Putra Malaysia, Selangor, Malaysia \\ ${ }^{*}$ Corresponding author, $\equiv$ e-mail: ratnashun@gmail.com
}

\begin{abstract}
Setting goals can be reviewed as aspirations for future betterment especially among adolescents. Goal-setting process involves aspects like future planning, principles, values, priorities, application of knowledge and decision making. This process varies according to individual needs and requires different approaches and guidance. Literature review prevailed that the essential ingredient of Solution-focused approach is setting goals. Solution-focused techniques found to be vital and crucial in assisting adolescents to set goals. Two objectives were drawn through literature reviews. Objective one is to determine the effectiveness of SFGW in increasing adolescent's goal orientation behavior mean score between pre-test, post-test and follow-up test. And, the second objective is to compare the effects between SFGW intervention module (treatment group) and traditional module (control group) on goal orientation mean score for post-test and follow-up test. This is a true experimental with pre-test and post-test design using Solution-focused module and administration of questionnaires for data collection. A total of 66 samples who met the inclusion requirement were assigned randomly to experimental $(n=32)$ and control $(n=34)$ groups using paired-matched design. The samples in experimental group were given treatment using the SFGW intervention program for seven weeks. After the completion of the treatment, posttest and followup test were carried out and data was collected using Goal Orientation Scale. The collected data was analyzed using descriptive statistics, independent samples t-test, and one-way repeated measure ANOVA. The study discloses that SFGW does significantly affect the level of goal orientation behavior among Malaysian adolescents.
\end{abstract}

Keywords: Adolescents, goal orientation behavior, solution-focused theory, goal setting

How to Cite: Shunmugam, R., Noah, S., \& Jaafar, W. (2019). Ingraining goal orientation behavior among Malaysian adolescents using Solution-focused group work (SFGW). COUNS-EDU: The International Journal of Counseling and Education, 4(4), 140-147. doi:http:// doi.org/10.23916/0020190424640

\section{Introduction}

It is timely that Ministry of Education has had introduced National Educational Blueprint (2013) with one of the focus is to produce a well-informed students, be it academically or non-academically. Schools are encouraged to create a harmonious environment for students to explore themselves and provide opportunities for them to correct their behavior. Since adolescence is a crucial stage to develop their strengths towards positive living, they need to be empowered with confidence and ability to figure out solutions for their own problems (Morton \& Montgomery, 2013). Razali, Dokoushkani \& Rajendran (2013) clinched that Malaysian adolescents face problems in schools and at home which in return challenges their adolescence life cycle. Kuldas, Hashim \& Hairul (2015) viewed adolescents involvement in at-risk activities are associated with factors like negative social environment, low self-concept, bad parental influence and disadvantaged socioeconomic background. Current behavioral problems portrayed by Malaysian adolescents are suicidal, internet addiction, drug offences, stealing, house-breaking (Mohd. Isa. Hashim, Kaur \& Ng, 2016; Tin, Jessemine Khoo, Wong \& Tan, 2017). Lee (2014) reported that juvenile crimes show an increasing trend from 3700 cases in 2012 to 7816 in 2013 . Malaysian adolescents 
also depicted as have no appropriate knowledge of life skills such as refusal skills, communication skills, anger control and coping mechanism with emotion (Marjan \& Hayati, 2017). Apart from this, Malaysian adolescents facing mental illness like depression and various addictions like internet and substances uses. The cause of behavioral problems among adolescents is their failure to cope with daily life stressors. Such failure leads adolescents to inability to control behaviors and involved in undesirable activities.

Despite all the hindrance factors, there are many adolescents who succeeded within same unfortunate background. They have shown satisfactory ability in using their cognitive tasks to face challenges and attain success. Moshman (2011) affirmed that, despite the difficulties and stereotypes by the adults, adolescents often demonstrate remarkable competence in leading their adolescence world. This contradict view requires empirical evidence on what makes them to be successful despite all the challenges. Hence, Kuldas et al. (2015) recommend the development of a care giving relationship model for Malaysian adolescents to boost their cognitive tasks performance and resilience. Thus, all they need to grow as positive adolescents are be recognized, appreciated, and acknowledged by adults (Moshman, 2011). In line with this, current study aimed to assist the adolescents to create their own goals and challenge their thoughts and ultimately achieve the goals set in a group setting.

Literature reviews (Kuldas et al. 2015; Abdullah, Ortega, Ahmad, Ghazali, 2015; Mohd Isa, et al. 2016; Tin, et al. 2017) suggested early psycho-educational interventions in schools to assist adolescents in coping with social issues. Researchers suggest teachers and school counselors to help adolescents by increasing programs focusing on coping skills and emotional regulative strategies. As to laud the suggestions from previous researches, current study develops SFGW intervention program which aimed to increase adolescents' goal orientation behavior. The dependent variable is found to be a core element in helping adolescents to create suitable social skills and ultimately lead to a successful adulthood.

In grounding a theoretical framework for studying the instillation of goal orientation behavior using Solution-Focused group work, goal-setting theory of motivation provides a useful model. According to Locke \& Lathem (1990), cognitive and motivational factors play vital role in determining human behaviors. Human behaviors are constantly influenced by conscious purposes, plans, intentions, tasks and interest. In essence, human behaviors are the product of consciously goal directed and performed with intention. With acknowledgement that not all human behavior performed under fully conscious control, this theory ascertains that goals do play significant role in formation of human behavior. The module developed based on the Solution-focused tenets and goal-setting theory could explain the significance of empowering the adolescents to focus on solutions to their problems. Empowering adolescents can be done by encouraging them to plan, set goals, to experience, to review goals, to reframe obstacles and to celebrate little change that they observe is happening to them. Solution-focused setting goals tenet encourages adolescents to frame their own goals which eventually they will practice and strive to achieve. Effective goal setting will increase individual's confidence, which ultimately develops their sense of competency and become productive regardless of their basis. Apart from that, as mooted and practiced in the interventions by many researches (Paul, 2017; Zainudin, Lee, Ng \& Tan, 2014; Carroll, Gordon, Haynes \& Houghton, 2013 \& Moeller, Janine, Theiler \& Wu, 2012), support is found to be important in assisting adolescents to achieve their goals. Solution-focused techniques like compliment and exceptions are souls to provide support and encourage the adolescents to work more to achieve goals. In conclusion, even though other variables might influence the success of adolescents, personal goal-setting or goal orientation behavior (GOB) found to be significant. This results in the formulation of H01 - There is no difference of goal orientation behavior means score at pre-test, post-test and follow-up test, H02 - There is no difference of goal orientation behavior means score between SFGW intervention module compared to traditional module towards adolescents at post-test and H03 - There is no difference of goal orientation behavior means score between SFGW intervention module compared to traditional module at follow-up test.

\section{Method}

The first step involves in the study is the formulation of research hypotheses. Through literature reviews, three research hypotheses formulated and terms that used in the research were defined. Secondly, experimental research design established. The internal and external threat were identified and verified accordingly. This is a very important aspect of experimental design as to ensure that independent variable is the only cause for the effect on dependent variables. And, based on Sidek Module Development Model (SMDM), SFGW was developed and validated. 
After that, pilot study was carried out. Pilot study is viewed as one of the significant steps in this study to ensure that the instruments developed measure the intended variables as proposed by the conceptual framework. The pilot study enables to the identification of inappropriate items and unanticipated problems in the instruments. The current study adapted the Goal Orientation Scale and the administration on Malaysian adolescents revealed .722 of Alpha Cronbach value. Permission was obtained from the Ministry of Education to conduct the research. Permission letter from the Educational Planning and Research Division (EPRD) was secured and the letter to use the school platform for the experiment will be sent to participating school Principal. Upon obtaining the permission, a number of 30 students were recruited for the pilot study. Finally, the researcher discussed with the supervisors of this study before an invitation to participate made to participants in Selangor. As soon as the pilot study completed and the reliability and validity of the instruments established, the actual data collection procedure was implemented.

Determining sample size is an essential step in designing the research. It is important because adequate sample size ensures reliable results. To ensure that the study has sufficient statistical power to reduce Type II error, G-Power 3.1 analysis was conducted. Statistical power is a measure that a researcher identifies the statistical significance in a sample if the effect exists in the real population. Power is a function factor like sample size, effect size, significance level, and the power of the statistic used. As to identify if there is statistically significant difference when the null hypothesis is rejected, power (Cohen, 1988) justifies these levels of effect sizes. The result indicated that a total sample of 52 people needed to detect medium effects $(d=.5)$ with using power of $80 \%$, t-test between means with alpha at .05 . F-test ANOVA required 10 people to detect medium effects $(\mathrm{d}=.5)$ with using $80 \%$ power, means with alpha at .05. And, a total of 14 people needed to detect medium effects $(\mathrm{d}=.5)$ using $80 \%$ power using F-test MANOVA between means with alpha at .05 . A total of 66 samples were found sufficient to determine the effect of the intervention as in the study. Therefore, the current study used 66 samples who had been assigned to experimental $(n=32)$ and controlled $(n=34)$ groups randomly.

The selection of the samples conducted after the permission obtained from Ministry of Education, Selangor State Educational Department and the schools. The announcement was made by the school counselors about the intervention program. Researcher accompanied by school counselor distributed the consent form to all intended Form 2 students. After that, school counselor made the arrangement for the researcher to meet the students who have obtained their parental approval. A relief slot of 1 hour 10 minutes was arranged by the relief teacher. The selection of the participants was based on following condition inclusive criteria: 1) All Form 2 students in public secondary schools in the district of Petaling Perdana, and 2) Participants are able to communicate and write in English Language.

When a list of interested and eligible participants secured, the questionnaire was administered. The school counselor assisted the researcher to gather all Form 2 students in the school hall on the first day of meeting. After the introduction session by the school counselor, a briefing session about the intervention program was led by the researcher. Once students are briefed about the purpose of the meeting, students were asked to respond to the questionnaire. The competency in English required as the instrument were prepared in English and treatment too carried out in English. Students who are not interested and not competent in English withdrew from the pretest.

After the completion of the pretest, the mean of each participant was determined using the SPSS Version 24. Participants who scored between -1 and +1 standard deviation from the mean will be selected as samples. This method ascertains that all the individuals from the population have the equal chance to participate and those who scored extremely low or high had been excluded. A total of 66 samples were selected and assigned to experimental (32 samples) and control (34 samples) groups using matched pair randomization. Later, samples from experimental group were assigned to 4 sub-groups each group consists of eight to nine participants. Then, experimental groups were treated with SFGW intervention for seven consecutive weeks and on 8th week the posttest was administered. Lastly, on the 12th week participants were asked to answer the questionnaire again and follow-up data was collected. The data was analyzed using the SPSS. Both descriptive and inferential statistics will be used to analysis data obtained. The study also sought to examine the relationship among SFGW (independent variable) and goal orientation behavior (dependent variable). Table below illustrates the types of statistical analysis for this study based on the research hypotheses formulated. 
Table 1. Statistical Analysis based on Research Questions/ Hypotheses

\begin{tabular}{|c|c|}
\hline Research Hypotheses & Type of analysis \\
\hline SFGW is not a valid and reliable module & Descriptive Statistic \\
\hline $\begin{array}{l}\mathrm{H}_{0} 1 \quad \text { There is no difference of goal orientation behavior means } \\
\text { score at pre-test, post-test and follow-up test }\end{array}$ & Repeated Measures ANOVA \\
\hline $\begin{array}{l}\mathrm{H}_{0} 2 \text { There is no difference of goal orientation behavior between } \\
\mathrm{SFGW} \text { intervention module (treatment group) and traditional } \\
\text { module (control group) at post-test. }\end{array}$ & Independent Sample T-test \\
\hline $\begin{array}{l}\mathrm{H}_{0} 3 \quad \text { There is no difference of goal orientation behavior between } \\
\text { SFGW intervention module (treatment group) and traditional } \\
\text { module (control group) at follow-up test. }\end{array}$ & Independent Sample T-test \\
\hline
\end{tabular}

\section{Results and Discussions}

This study aimed to determine the effect of SFGW in increasing the goal-orientation behavior among Malaysian adolescents. A total of three hypotheses derived from the research question; (1) H01 To determine the effectiveness of SFGW in increasing adolescents' goal orientation behavior mean score (pretest, posttest and follow-up test); (2) H02 - To compare the effects of SFGW intervention module compared to traditional module towards adolescents' goal orientation behavior means score at posttest; (3) H03 - To compare the effects of SFGW intervention module compared to traditional module towards adolescents' goal orientation behavior mean score for follow-up test.

$\mathrm{H}_{0} 1$ : There is no difference of goal orientation behavior means score at pre-test, post-test and follow-up test

Table 2. Mean of goal orientation behavior means score in experimental and control group between pre-test, post-test and follow-up test

\begin{tabular}{|c|c|c|c|c|c|c|c|}
\hline \multirow[t]{2}{*}{ Evaluation } & \multicolumn{4}{|c|}{ Treatment Group } & \multicolumn{3}{|c|}{ Control Group } \\
\hline & & $\mathbf{N}$ & $\mathbf{M}$ & SD & $\mathbf{N}$ & $\mathbf{M}$ & SD \\
\hline Pre-test & 32 & & 2.26 & 0.13 & 34 & 2.15 & 0.28 \\
\hline Post-test & & 32 & 3.66 & 0.28 & 34 & 2.16 & 0.28 \\
\hline Follow-up test & & 32 & 3.68 & 0.24 & 34 & 2.09 & 0.38 \\
\hline
\end{tabular}

To test this hypothesis, one-way repeated measure ANOVA was used. The use of one-way repeated measure ANOVA is to analysis the difference between pretest, posttest and follow-up test of goal orientation behavior scores of same samples. Table 5.11 indicates that there is a significant difference in self-efficacy between treatment group $(\mathrm{M}=2.26 \mathrm{SD}=0.13)$ and control group $(\mathrm{M}=2.15, \mathrm{SD}=0.28)$ at pretest. At post-test the scores for treatment group is $(\mathrm{M}=3.66, \mathrm{SD}=0.28)$ and control group $(\mathrm{M}=2.16$, $\mathrm{SD}=0.28)$. And, at follow-up test the result in treatment group is $(\mathrm{M}=3.68, \mathrm{SD}=0.24)$ and control group is $(\mathrm{M}=2.09, \mathrm{SD}=0.38)$. The results indicate that there is a difference in mean scores between pretest, post-test and follow-up test. Mauchly's test indicated that the assumption of sphericity had been violated, $\chi 2(2)=39.333, p<.05$. Therefore degrees of freedom were corrected using Greenhouse-Geisser estimate of sphericity $(\varepsilon=.685)$. The results show that the goal orientation behavior mean score was significantly affected by the time, $\mathrm{F}(1.37,89.09)=41.667, \mathrm{p}<.001, \eta \mathrm{p}^{2}=.391$. 
Table 3. The results of Bonferroni comparisons tests for goal orientation behavior

Pairwise Comparisons

\begin{tabular}{|c|c|c|c|c|c|c|}
\hline \multirow{2}{*}{ factor1 } & \multirow{2}{*}{ factor1 $^{(\mathrm{J})}$} & \multirow{2}{*}{$\begin{array}{c}\text { Mean } \\
\text { Difference (I-J) }\end{array}$} & \multirow{2}{*}{ Error } & \multicolumn{2}{|c|}{$\begin{array}{l}\text { 95\% Confidenc } \\
\text { Difference }^{\mathrm{b}}\end{array}$} & \multirow{2}{*}{$\begin{array}{l}\text { Interval for } \\
\text { Upper Bound }\end{array}$} \\
\hline & & & & Sig. ${ }^{b}$ & er Bound & \\
\hline \multirow[t]{2}{*}{1} & 2 & $-.678^{*}$ & .090 & .000 & -.900 & -.457 \\
\hline & 3 & $-.651^{*}$ & .103 & .000 & -.904 & -.398 \\
\hline \multirow[t]{2}{*}{2} & 1 & $.678^{*}$ & .090 & .000 & .457 & .900 \\
\hline & 3 & .028 & .050 & 1.000 & -.095 & .151. \\
\hline \multirow[t]{2}{*}{3} & 1 & $.651^{*}$ & .103 & .000 & .398 & .904 \\
\hline & 2 & -.028 & .050 & 1.000 & -.151 & .095 \\
\hline
\end{tabular}

***. The mean difference is significant at the .001 level.

b. Adjustment for multiple comparisons: Bonferroni.

Bonferroni comparisons tests show that there was a statistically significant difference in the goal orientation behavior mean score for the following pairs: Pre-test and post-test $(\mathrm{p}<.001)$, Pre-test and follow-up test $(p<.001)$, but not for post-test and follow-up test $(p=1.00)$. Therefore, we can conclude that the SFGW intervention module does affect adolescents' goal orientation behavior between pre-test and post-test and remains unchanged between post-test and follow-up test. The analysis showed that the partial eta squared is .391 which is falls under the large effect size. Thus, hypothesis one was rejected.

The second objective of the study is to compare the effects between SFGW intervention module (treatment group) and traditional module (control group) on adolescent's goal orientation behavior mean score for post-test and follow-up test. Two hypotheses ( $\mathrm{H} 02$ and H03) were drawn and tested using independent-samples t-tests. The analysis was conducted to compare the adolescent's self-efficacy mean score for post-test and follow-up test between treatment group and control group. The results of the finding presented below.

$\mathrm{H}_{0} 2$ There is no difference of goal orientation behavior between SFGW intervention module (treatment group) and traditional module (control group) at post-test.

Table 1.4. Results of independent sample t-test between treatment group and control group on adolescents' goal orientation behavior mean score at post-test.

\begin{tabular}{llllll}
\hline GOS & $\mathrm{N}$ & $\mathrm{M}$ & $\mathrm{SD}$ & $T$ & sig- $t$ \\
\hline Treatment & 32 & 3.66 & 0.28 & 21.642 & $.000^{*}$ \\
Control & 34 & 2.16 & 0.28 & & \\
\hline
\end{tabular}

Note: *** Significant at $\alpha=.005$

To answer the second hypotheses, independent-samples t-tests were conducted to compare the adolescent's goal orientation behavior mean score for post-test and follow up test between treatment group and control group. For post-test, there was a significant difference in the adolescent's goal orientation behavior mean score for treatment group $(\mathrm{M}=3.66, \mathrm{SD}=0.28)$ and control group $[\mathrm{M}=2.16, \mathrm{SD}=0.28 ; t$ $(64)=21.642, p<.000]$. The effect size is large $(d=5.33)$. An inspection of the two means suggest the treatment group respondents have higher mean score compared to control group respondents.

$\mathrm{H}_{0} 3$ There is no difference of goal orientation behavior between SFGW intervention module (treatment group) and traditional module (control group) at follow-up test. 
Table 5. Results of independent sample t-test between treatment group and control group on adolescent's goal orientation behavior mean score for follow- up test

\begin{tabular}{llllll}
\hline GOB & $\mathrm{N}$ & $\mathrm{M}$ & $\mathrm{SD}$ & $T$ & sig-t \\
\hline Treatment & 32 & 3.68 & 0.24 & 20.255 & $.000^{*}$ \\
Control & 34 & 2.09 & 0.38 & & \\
\hline
\end{tabular}

Note: ${ }^{* *}$ Significant at $\alpha=.001$

For follow up test, there was a significant difference in the adolescent's goal orientation behavior mean score for treatment group $(\mathrm{M}=3.68, \mathrm{SD}=0.24)$ and control group $[\mathrm{M}=2.09, \mathrm{SD}=0.38 ; t(64)=$ $20.255, p<.000]$. The effect size is large $(d=4.99)$. An inspection of the two means suggest the treatment group respondents have higher mean score compared to control group respondents. Overall, statistical analysis indicates that the intervention (SFGW) has been effective in increasing the goal orientation behavior in the experimental group. Therefore, all three null hypotheses were rejected.

The results reveal similarities with other findings of previous studies such as Paul, (2017); Zainudin, et al. (2014); Carroll, et al. (2013); Moeller, et al. (2012). In the cited studies, Solution-focused approach has been effective in the intervention of increasing goal orientation behavior. Their findings support the current finding that Solution-focused approach had been a tool in assisting adolescents to achieve their goals. As literature reviews pointed out, solution-focused techniques like compliment and exceptions are souls to provide support and encourage the adolescents to work more to achieve goals (Law \& Jacob, 2013; Trepper, et al. 2011).

It is evident that many researches viewed goal orientation behavior as a catalyst for children and adolescents well-being. Such claim is broadly consistent with Moeller, et al. (2012) longitudinal study which reveals that personal goal-setting and students' achievement in Spanish language class found to be interrelated. A short term longitudinal study of goal setting and decision making over 14 months of college life was deemed to established that goals changes over the year but setting goals lead a successful college life (Katheleen \& Lacey, 2014). Carroll, et al. (2013) suggest that a specific goal setting programs should be developed as to assist adolescents to set clear goals and provide essential support through the process.

Many findings found that Solution-focused approach in the research has successfully managed adolescent's academic stress (Busari, 2016), enhance adolescents social competency (Ates, 2016), assisted both victims perpetrators of bullying in schools (Paolini, 2016) and other aspects of adolescents well-being. Goal orientation behavior plays an important role in assisting success in adolescent's life. Like Guthrie, Klauda \& Ho (2013) suggests in their study, the current result concludes that, goal orientation behavior is a must in adolescents to successfully achieve their desires. The study can confidently claim that SFGW intervention is at par to provide skills of setting goals, reframe the goals and foresee success in achieving the goals. Current study is advocating the suggestion made where the results shows that SFGW intervention program is one of such goal setting program.

The results show that the techniques in SFGW intervention increases goal orientation behavior in adolescents. As in this study, the analysis showed that the eta squared is .957 which is falls under the large effect size. These results can be illustrated based on literature reviews which ascertain that the essential ingredient of Solution-focused approach is setting goals. Solution-focused techniques found to be vital and crucial in assisting adolescent's to set goals. From the initial stage, adolescents asked to set clear, specific and attainable goals. Solution-focused setting goals tenet encourages adolescents to frame their own goals which eventually they will practice and strive to achieve. The goals can be measured using the scaling techniques, where the adolescents will scale from $0-10$. Scaling the goals helps the adolescent's to see their confidence level in achieving goals (Trepper, et al. 2011). Apart from that, as mooted and practiced in the interventions by many researches (Paul, 2017; Zainudin, et al. 2014; Carroll, et al. 2013; Moeller, et al. 2012), support is found to be important in assisting adolescents to achieve their goals. 


\section{Conclusions}

With the references to literature reviews and the results of the study, researcher can ascertain that SFGW intervention program able to increase adolescent's goal orientation behavior. The result of the study cannot be generalized to the population as a whole as the study limited to 66 participants from two schools in Selangor. A larger number of participants needed to make generalization. Hence, further research with larger number of participants and different research design like longitudinal study will be needed to validate the effectiveness of SFGW. This will further assist counselors or other stakeholders to groom a goal orientated young generations.

\section{References}

Abdullah, H., Ortega, A., Ahmad, N., Ghazali, S. (2015). aggressive and delinquent behavior among high risk youth in Malaysia. Asian Social Science. 11(16), 62-73.

Ates, B. (2016). Effect of solution-focused group counseling for high school students in order to struggle with school burnout. Journal of Education and Training Studi. 4(4), 27-34.

Busari, A. O. (2016). Solution focused social interest programme as treatment option. Journal of Mental Disorders Treatment. 2(2), 1-10.

Carroll, A., Gordon, K., Haynes, M \& Houghton, S. (2013). Goal setting and self-efficacy among delinquent, at-risk and not at-risk adolescents. Journal of Youth and Adolescence. 42(3), 431-443.

Guthrie, J. T., Klauda, S. L. \& Ho, A. N. (2013). Modeling the relationships among modeling the relationships among reading motivation, reading motivation, engagement and achievement engagement and achievement for adolescents. Reading Research Quarterly. 48(1), 9-26.

Kathleen, M. G. \& Lacey, R. C. (2014). Goals, styles, and decisions: Changes and interactions during the first year of college. American Journal of Psychology. 127(3), 383-396.

Kuldas, S., Hashim, S. \& Ismail, H. N. (2015). Malaysian adolescent students' needs for enhancing thinking skills, counteracting risk factors and demonstrating academic resilience. International Journal of Adolescence and Youth. 20(1), 32-47.

Lee, L. T. (2014, April 14). Juvenile crime on the rise. TheStarOnline, pp 2-3. Retrieved from https://thestar.com.my/

Locke, E.A. \& Latham, G.P. (1990). A theory of goal setting and task performance. New Jersey, United States: Prentice-Hall. Inc.

Marjan, M. \& Hayati, K. S. (2017). Life skills education for Malaysian institutionalized adolescents: knowledge needs and priorities: A qualitative pilot study. Iranian Journal of Public Health. 46(12), $1739-1741$.

Moeller, A. J., Janine, M., Theiler \& Wu, C. (2012). Goal setting and student achievement: A longitudinal study. The Modern Language Journal. 96 (2), 153-169.

Morton, M. H. \& Montgomery, P. (2013). Youth empowerment programs for improving adolescents' selfefficacy and self-esteem: A systematic review. Research on Social Work Practice. 23(1), 22-33.

Moshman, D. (2011). Adolescent rationality and development: Cognition, morality and identity. ( $\left.3^{\text {rd }} \mathrm{ed}\right)$. New York: Psychology Press.

Mohd. Isa, S., Hashim A.H., Kaur, M., Ng, CG. (2016). Internet addiction among adolescents in Malaysia: the prevalence and its association with attention deficit hyperactivity disorders (ADHD) symptoms. Malaysian Journal of Psychiatry E-Journal. 25(1), 3-18.

Paolini, A. C. (2016). Utilizing solution focused brief counseling with primary and middle school grades: Helping the perpetrator and the victim mitigate effects of bullying introduction. Overview of Bullying. 10(2), 50-60.

Paul, D. G. (2017). The effects of a goal setting intervention on delinquent adolescent group treatment outcomes. (Unpublished Doctoral thesis).

Razali, A., Dokoushkani, F. \& Rajendran, K. (2013). What does literature say about student at risk? Psychology and Behavioural Sciences. 2(2), 51-58.

Tin Zhi Ling, Jessemine Khoo Ai Pheng, Wong Wan Sin \& Tan Soon-Aun. (2017). The relationship between personality traits and behavioral problems among adolescents in Malaysia. Sains Humanika. 3(2), 29-35.

Trepper, Terry \& Mccollum, Eric \& De Jong, Peter \& Korman, Harry \& Gingerich, Wallace \& Franklin, 
Cynthia.(2011).SolutionFocused_BriefTherapy_Treatment_Manual1.10.1093/acprof:oso/978019 5385724.003.0015.https://www.researchgate.net/publication/290320627_Solution_Focused_Bri ef_Therapy_Treatment_Manual1. 